\title{
The role of the socio-economic environment on medical outcomes after ST-segment elevation myocardial infarction
}

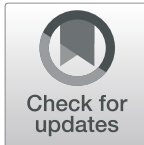

\author{
Christian Roth ${ }^{1 *}$, Rudolf Berger ${ }^{2}$ and Michael Kuhn ${ }^{3}$
}

\begin{abstract}
Background: According to the World Health Organization, coronary artery disease (CAD), including ST-segment elevation myocardial infarction (STEMI), is the most common cause of death worldwide as well as in Europe and Austria. There is valid data on the impact of conventional risk factors on the medical outcomes for STEMI patients. However, only few studies examine the role of the socio-economic environment for medical outcomes. The main task of this study is to investigate if the socio-economic environment of patients who underwent percutaneous coronary intervention (PCI) after STEMI has an impact on the distribution of risk factors and medical outcomes.

Methods: The study focuses on the population of the City of Vienna, Austria, and includes 870 STEMI patients, who underwent PCl at the General Hospital of Vienna (AKH Wien) between 2008 and 2012. The following data were collected: conventional risk factors (hypertension, hyperlipidemia, diabetes, overweight, smoking, family history and vascular disease) and socio-economic indicators of the patient's residential district (number of residents, income pre-tax, residents per general practitioner, residents per internal specialist, compulsory education only, academic degree and rate of unemployment). Cox regressions were performed to evaluate the impact of socio-economic environment and conventional risk factors on survival.
\end{abstract}

Results: Most of the conventional risk factors show a significant difference between deceased and surviving patients. The study revealed significant differences across districts in relation to the socio-economic background of STEMI patients. Surprisingly, medical outcomes, as measured by the survival of patients, are significantly related to a patient's district of residence ( $p$-Value $=0.028$ ) but not in a systematic way as far as the socio-economic environment of these districts is concerned.

Conclusions: The study provides intuitive evidence for a hitherto understudied Central European context on the link between socio-economic environment and conventional risk factors at population level and the link between conventional risk factors and survival both at the population at the individual level. While this is in line with previous evidence and suggestive of the incorporation of measures of socio-economic status (SES) into policy \& guidelines toward the management of CAD, more data on the SES - STEMI nexus are needed at individual level.

Keywords: ST-segment elevation myocardial infarction, Socio-economic environment, Conventional risk factors

\footnotetext{
* Correspondence: christian.roth@meduniwien.ac.at

'Department of Internal Medicine II, Cardiology, Medical University of Vienna,

Waehringer Guertel 18-20, 1090 Vienna, Austria

Full list of author information is available at the end of the article
}

(c) The Author(s). 2019 Open Access This article is distributed under the terms of the Creative Commons Attribution 4.0 International License (http://creativecommons.org/licenses/by/4.0/), which permits unrestricted use, distribution, and reproduction in any medium, provided you give appropriate credit to the original author(s) and the source, provide a link to the Creative Commons license, and indicate if changes were made. The Creative Commons Public Domain Dedication waiver (http://creativecommons.org/publicdomain/zero/1.0/) applies to the data made available in this article, unless otherwise stated. 


\section{Background}

According to the World Health Organization (WHO), coronary artery disease (CAD) is the most common cause of death worldwide. In 2015, 8.76 million people died because of CAD, amounting to $15.5 \%$ of all deaths [1]. According to the "Heart disease and stroke statistics 2016" by the American Heart Association (AHA), the total prevalence of CAD in the United States is $6.2 \%$ in adults aged 20 years and over. CAD prevalence is $7.6 \%$ in men and $5.0 \%$ in women [2]. In Europe, every sixth man and every seventh woman is dying from myocardial infarction [3]. Diseases of the cardiovascular system are the most frequent cause of death in Austria as well. A recent report by Statistik Austria shows that $37.8 \%$ of all male decedents and $47.4 \%$ of all female decedents died because of CAD [4].

Several risk factors are responsible for the appearance of CAD and the potential risk of ST-segment elevation myocardial infarction (STEMI). Conventional risk factors, including hypertension, hyperlipidemia, diabetes mellitus, overweight, smoking, family history, cerebrovascular disease (CVD), peripheral vascular disease (PVD) and age, influence the occurrence and progression of CAD. Therefore, they have a clear impact on the prognosis and medical outcome for these patients [5-14].

Aside from the conventional risk factors, there is a notable influence of a person's socio-economic status (SES). In general, SES is the extent of a person's access to collectively desired resources, such as material goods, money, power, friendship networks, healthcare, leisure time or educational opportunities, and is a fundamental aspect in social and health sciences $[15,16]$. Investigations of SES and statistics based on indicators of SES are necessary to quantify the level of social stratification or inequality in or between societies. These analyses are important to capture and understand changes of social structures and the intergenerational change of social status over time. Finally, SES matters because it is related to health and life outcomes and is therefore an important determinant of the performance of health care systems $[15,16]$. Studies have shown that a low SES in patients with CAD is associated with a higher rate of conventional risk factors, unfavorable health in general and more cardiovascular events such as STEMI [17-21]. It is also associated with a higher morbidity, mortality and more complications after heart surgery like coronary artery bypass grafting [22-25]. A low SES has also been linked to disproportional use of health care in regard to other diseases [26].

Depending on the availability of data, SES is measured either at the individual level or in a more summarily way at the level of the individual's residential environment or neighbourhood [27-29]. Studies based on such "neighbourhood" indicators have found a significant impact of the socio-economic environment on individual health behaviour and outcomes for several regions and cities $[17,20,30]$. This includes health outcomes in respect to $\operatorname{CAD}[18,21,23]$.

The place of residence gives information about the socio-economic environment of the patient. It also shows the distance from the patient's home to a hospital, as it is important to perform PCI in STEMI patients as quickly as possible. Patients who live closer to a hospital have an advantage compared to those who live farther away [31, 32]. Furthermore, the place of residence shows if a patient lives in a favorable area of a city, reflecting the socio-economic surroundings.

A relationship between SES and health behaviours, such as smoking and drinking, and outcomes, such as morbidity and mortality for chronic disease and, notably, coronary heart disease, has been observed for a long time [30, 33]. Strikingly, the vast majority of these studies are set against the background of Anglo-Saxon countries (US, UK and Australia) with few additional studies from Scandinavia. In contrast, insights on the impact of SES on the outcomes after STEMI [21] are sparse, especially for continental European countries with their distinct social and welfare state environment.

This study seeks to provide some insights by studying the relationship between the socio-economic environment at residential district level in the City of Vienna, Austria, and (i) the prevalence of conventional risk factors at district level, as well as (ii) health outcomes for a population of patients undergoing PCI after STEMI at the Vienna General Hospital as a single high volume center. The aims are to identify correlations between SES environment and the prevalence of risk factors and to establish whether residential district has an impact on the medical outcomes for STEMI patients. An understanding of the role of socio-economic inequalities for medical outcomes is important to better target health care resources and to provide optimal medical treatment for patients undergoing PCI after STEMI.

\section{Methods \\ Study population}

All patients presented with STEMI on Saturday or Sunday at the AKH Wien within the time span 2008 until 2012 were included in the study. Restricting the inclusion to weekend days was a deliberate decision, as the AKH Wien is the only hospital in charge of the treatment of STEMIs during weekends. Hence it is guaranteed that the study population represents a balanced mix of patients from all over Vienna.

Each coronary angiogram was executed by experienced interventionalists. The coronary angioplasty and 
the medical treatment were achieved according to the ESC guidelines [3].

After clarifying the survival status, all patients in the database were anonymized using a unique patient identification (ID). This study is approved by the ethics committee of the Medical University of Vienna (MUW) (EK Nr. 972/2011) and is also in line with the Declaration of Helsinki.

\section{Endpoint}

The primary endpoint of the study was the survival of patients. To determine date and cause of death of each patient the database was synchronized with the Austrian Death Registry database (Statistik Austria) at the end of the follow-up period. The due day of the data requested was the 31st of December 2014.

\section{Data collection}

Suitable patients were identified via the corresponding database of the catheter laboratory (Cardio-Report). The angiographic characteristics were collected from this database. Baseline characteristics and conventional risk factors were collected from the hospital information system (Krankenhausinformationssystem - KIS). All data was aggregated in an already existing comprehensive database, which has been built in close cooperation with the Center for Medical Statistics, Informatics, and Intelligent Systems (CeMSIIS) of the MUW using the Research Documentation and Analysis (RDA) IT-system.

\section{Socio-economic environment}

Measures of the socio-economic environment in this study are based on the postal code of each patient. A first set of socio-economic indicators includes: place of residence, pre-tax income, educational background (compulsory education only, academic degree) and rate of unemployment. A second set relates to the primary health care system, measuring the per capita number of general practitioners and internal specialists of the area the patient lives in. These data were collected for each of Vienna's districts from Statistik Austria, Ärztekammer Wien and "Stadt Wien, Magistratsabteilung 23 - Wirtschaft, Arbeit und Statistik" [34-43]. To avoid statistical bias due to the development of the districts over time, all data was collected for each individual year from 2008 through 2012.

\section{Statistical analysis}

The statistical analysis was performed by using SPSS (Version 24.0). Categorical variables are shown as counts or percentages, as appropriate. Categorical data is compared by crosstabs using Pearson's chi-square test. Continuous variables are shown as median with interquartile range (IQR) or mean $\pm S D$, as appropriate, and are compared using ANOVA. To detect a possible relation between socio-economic environment and place of residence the correlation was calculated. To evaluate the impact of variables on survival, Cox regression models were calculated. Kaplan-Meier analysis was used to estimate the cumulative probability of reaching an endpoint (survival) and the log-rank test was used to assess survival differences. All $p$-values under 0.05 are considered statistically significant. To analyze survival over a longer time span and to employ a bigger population sample, the population examined in the survival analysis was extended to also include STEMI patients from 2000 to 2007. Thus, 1605 patients with 356 endpoints were included in the survival analysis covering the overall time span 2000-2012.

\section{Results}

Baseline characteristics

A total of 870 patients with STEMI -- 613 male and 257 female patients with a mean age of $62( \pm 13.83)$ years -underwent $\mathrm{PCI}$ in a high volume center (AKH Wien) between 2008 and 2012. The baseline characteristics of the patient population, including epidemiological data and conventional risk factors, are given in Table 1.

Height and weight were collected from 526 patients. The mean body-mass-index of the population was 27.7 $( \pm 5.037) \mathrm{kg} / \mathrm{m}^{2}$ and more than three-fourths $(76.8 \%)$ of the patients showed overweight with a BMI bigger than $25 \mathrm{~kg} / \mathrm{m}^{2}$.

More than half of all patients $(n=870)$ showed up with hypertension $(57.9 \%)$ and hyperlipidemia (54.5\%). Table 1 shows that $17.6 \%$ of the patients suffered from diabetes mellitus and $46.8 \%$ were current or previous smokers. A positive family history of cardiovascular events was shown in $15.5 \%$ of all patients. Furthermore, $10.6 \%$ of the patients had suffered from a myocardial infarction before. The main symptom of the patients was chest pain, with $83.9 \%$ presenting with CCS class III or IV.

\section{Angiographic characteristics}

The angiographic characteristics of the whole patient population are listed in Table 1, with values given in total and percentage. More than half of the population $(52.8 \%)$ had a one-vessel disease in the coronary angiography and could be treated with a single procedure (71.0\%). Almost all patients $(97.6 \%)$ were treated with drug-eluting stents. About two thirds of the patients received a total revascularization (77.7\%).

\section{Cause of death}

By the end of the observation period, 167 patients (19.2\%) had died. The due day was the 31st of December 2014. All deaths during the observational time were due to cardiovascular circumstances. Acute coronary syndrome (6.8\%), cardiomyopathy (6.2\%) and progression of coronary artery disease (5.2\%) were the most common 
Table 1 Patient characteristics

\begin{tabular}{|c|c|}
\hline & total $n=870$ \\
\hline \multicolumn{2}{|l|}{ Baseline characteristics } \\
\hline Age, years; mean $( \pm S D)$ & $61.73( \pm 13.83)$ \\
\hline Age > 62; n (\%) & $416(47.8)$ \\
\hline \multicolumn{2}{|l|}{ Gender } \\
\hline - Female; n (\%) & $257(29.5)$ \\
\hline - Male; n (\%) & $613(70.5)$ \\
\hline \multicolumn{2}{|l|}{ STEMI per year } \\
\hline - 2008; n (\%) & $199(22.9)$ \\
\hline - 2009; n (\%) & $113(13.0)$ \\
\hline - 2010; n (\%) & $210(24.1)$ \\
\hline - 2011; n (\%) & $202(23.2)$ \\
\hline - 2012; n (\%) & $146(16.8)$ \\
\hline Height, cm; mean $( \pm \mathrm{SD})$ & $172.58( \pm 0.091)$ \\
\hline Weight, kg; mean ( \pm SD) & $83.18( \pm 16.821)$ \\
\hline Body-Mass-Index, kg/m²; mean $( \pm$ SD) & $27.7( \pm 5.037)$ \\
\hline Overweight (BMI > 25); n (\%) & $404(76.8)$ \\
\hline Heart rate, bpm; mean $( \pm S D)$ & $74.35( \pm 14.488)$ \\
\hline Hypertension; n (\%) & $504(57.9)$ \\
\hline Systolic blood pressure, mmHg; mean ( $(\mathrm{SD})$ & $128.87( \pm 20.002)$ \\
\hline Diastolic blood pressure, mmHg; mean $( \pm \mathrm{SD})$ & $77.32( \pm 13.093)$ \\
\hline \multicolumn{2}{|l|}{ Diabetes mellitus } \\
\hline - NIDDM; n (\%) & $107(12.3)$ \\
\hline - IDDM; n (\%) & $46(5.3)$ \\
\hline Hyperlipidemia; n (\%) & $474(54.5)$ \\
\hline \multicolumn{2}{|l|}{ Smoker } \\
\hline - current; n (\%) & $319(36.7)$ \\
\hline - previous; n (\%) & $88(10.1)$ \\
\hline Family history; n (\%) & $135(15.5)$ \\
\hline Central vascular disease; n (\%) & $57(6.6)$ \\
\hline Peripheral vascular disease; n (\%) & $45(5.2)$ \\
\hline Prior myocardial infarction; n (\%) & $92(10.6)$ \\
\hline Prior PCl; n (\%) & $77(8.9)$ \\
\hline Prior coronary artery bypass graft; $n$ (\%) & $17(2.0)$ \\
\hline \multicolumn{2}{|l|}{ NYHA class } \\
\hline - Class l; n (\%) & $388(44.6)$ \\
\hline - Class II; n (\%) & $29(3.3)$ \\
\hline - Class III; n (\%) & $45(5.2)$ \\
\hline - Class IV; n (\%) & $284(32.6)$ \\
\hline \multicolumn{2}{|l|}{ CCS class } \\
\hline - Class l; n (\%) & $20(2.3)$ \\
\hline - Class II; n (\%) & $28(3.2)$ \\
\hline - Class III; n (\%) & $54(6.2)$ \\
\hline - Class IV; n (\%) & $676(77,7)$ \\
\hline
\end{tabular}

Angiographic characteristics
Table 1 Patient characteristics (Continued)

\begin{tabular}{|c|c|}
\hline & total $n=870$ \\
\hline \multicolumn{2}{|l|}{ Vessel disease } \\
\hline - 1VD; n (\%) & $459(52.8)$ \\
\hline - 2VD; n (\%) & $238(27.4)$ \\
\hline - 3VD; n (\%) & $140(16.1)$ \\
\hline - LM only; n (\%) & $33(3.8)$ \\
\hline \multicolumn{2}{|l|}{ Number of procedures } \\
\hline - one; n (\%) & $618(71.0)$ \\
\hline - two; n (\%) & $173(19.9)$ \\
\hline - three; n (\%) & $60(6.9)$ \\
\hline - > three; n (\%) & $19(2.2)$ \\
\hline \multicolumn{2}{|l|}{ Patients treated with } \\
\hline - drug-eluting stent; n (\%) & 849 (97.6) \\
\hline - bare-metal stent; n (\%) & $21(2.4)$ \\
\hline \multicolumn{2}{|l|}{ Re-catheterizations } \\
\hline$-<30$ days; $\mathrm{n}(\%)$ & $167(19.2)$ \\
\hline - 30 days - 6 months; $n(\%)$ & $32(3.7)$ \\
\hline - 6 months - 1 year; $n$ (\%) & $30(3.4)$ \\
\hline - > 1 year; $n$ (\%) & $23(2.6)$ \\
\hline \multicolumn{2}{|l|}{ Number of stents } \\
\hline - one; n (\%) & $593(68.2)$ \\
\hline - two; n (\%) & $162(18.6)$ \\
\hline - three; n (\%) & $67(7.7)$ \\
\hline - > three; n (\%) & $48(5.5)$ \\
\hline \multicolumn{2}{|l|}{ Revascularization } \\
\hline - total; n (\%) & $676(77.7)$ \\
\hline - partly; n (\%) & $194(22.3)$ \\
\hline \multicolumn{2}{|l|}{ Cause of death } \\
\hline Total death; n (\%) & $167(19.2)$ \\
\hline Cardiovascular, acute coronary syndrome; n (\%) & $59(6.8)$ \\
\hline Cardiovascular, coronary artery disease; n (\%) & $45(5.2)$ \\
\hline Cardiovascular, vitium; n (\%) & $9(1)$ \\
\hline Cardiovascular, cardiomyopathy; n (\%) & $54(6.2)$ \\
\hline
\end{tabular}

causes of death. All causes of death in total and percentages can be seen in Table 1 .

Incidence and mortality

Table 2 shows STEMI incidence and mortality (amongst STEMI patients) per district and age stratification. While the incidence rate relates to the residents per district, the mortality rate relates only to the STEMI's per district.

Over the five year period covered, the 1st district $(0.079 \%$ from $16,455, n=13)$, the 9 th district $(0.071 \%$ from $39,305, n=28)$ and the 20th district $(0.074 \%$ from $82,304, n=61)$ exhibit the highest incidence rates. The highest STEMI mortality rates are found in the 12th 


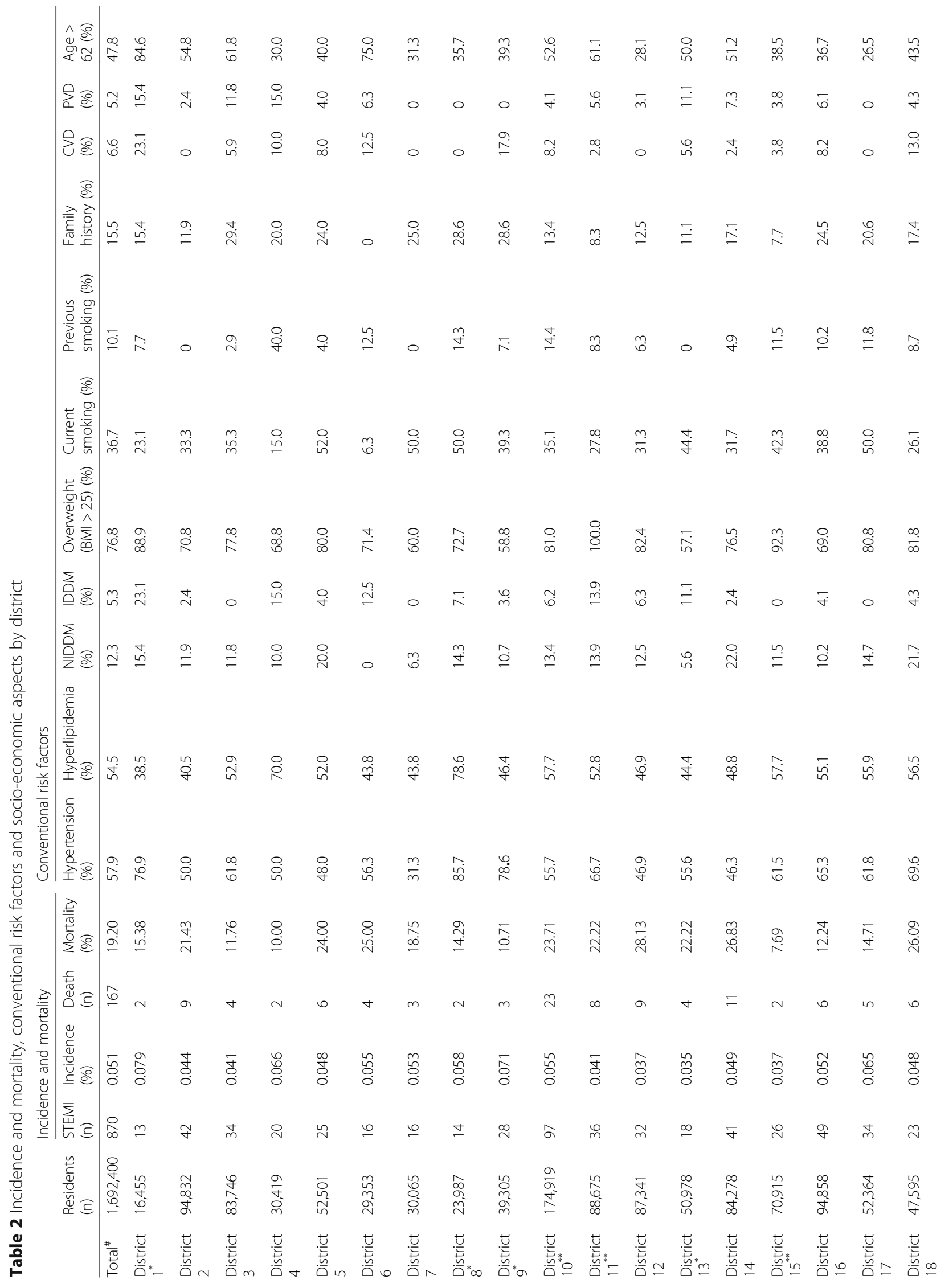




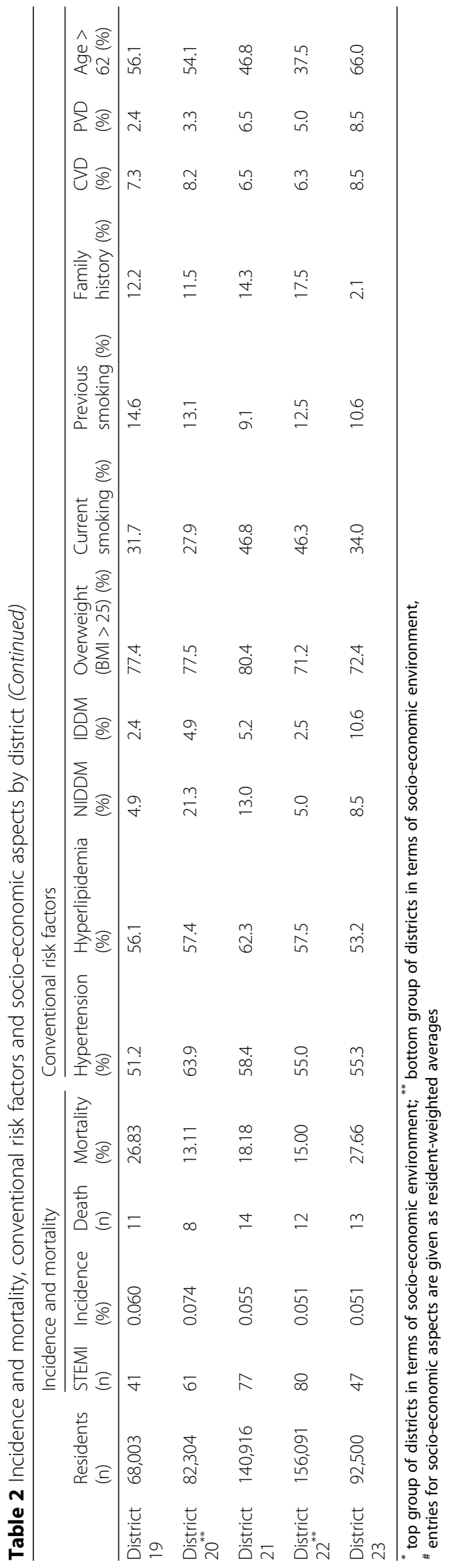




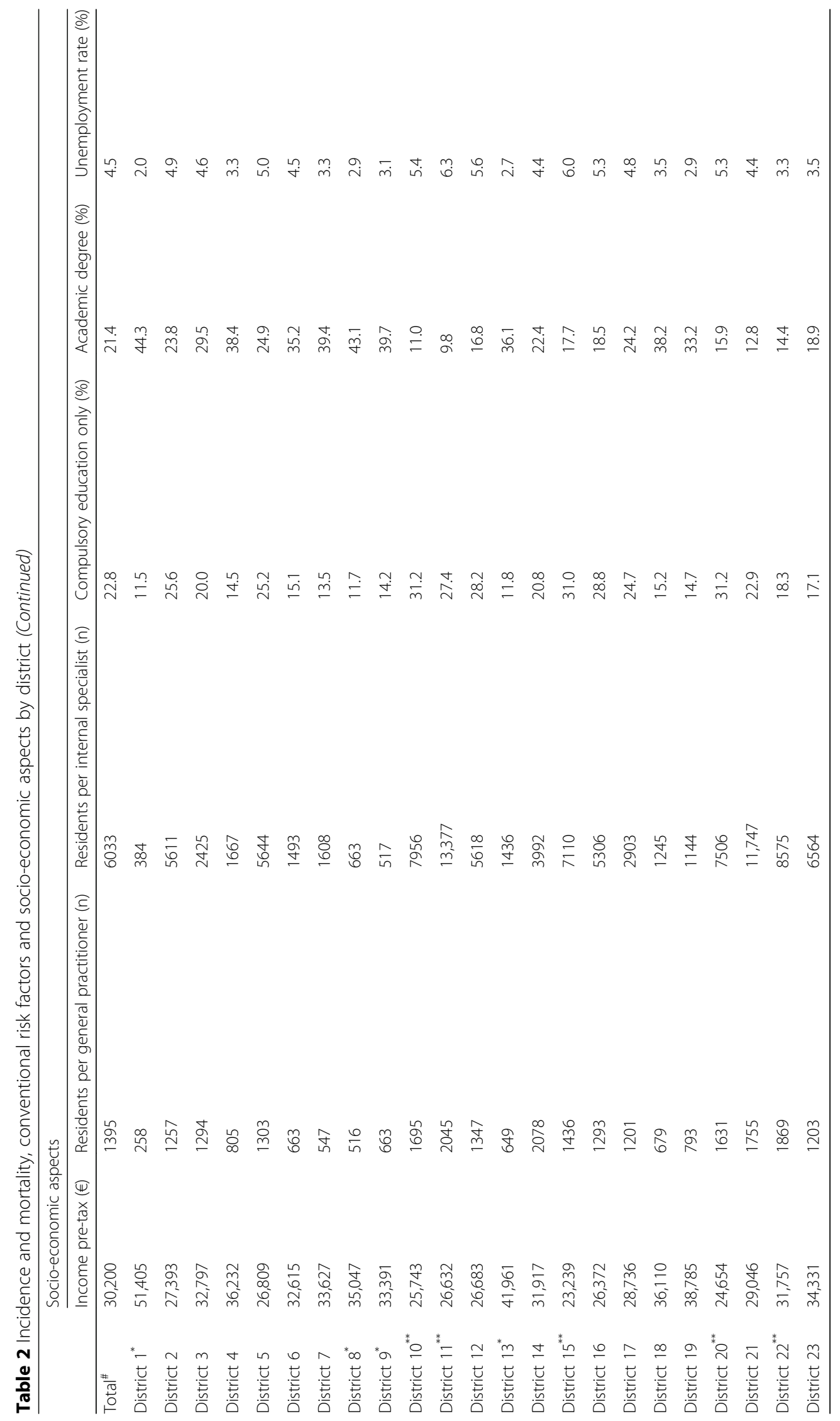


district (28.13\% from 32, $n=9)$, 14th district $(26.83 \%$ from $41, n=11)$, 19th district $(26.83 \%$ from $41, \mathrm{n}=11$ ) and 23 rd district (27.66\% from $47, n=13)$. The lowest STEMI mortality rates are found in the 4th district $(10.00 \%$ from $20, n=2)$, the 9 th district $(10.71 \%$ from $28, n=3)$ and the 15 th district $(7.69 \%$ from $26, \mathrm{n}=2)$. Further details are presented in Table 2.

\section{Conventional risk factors}

The distribution of the conventional risk factors per district is also shown in Table 2. The following conventional risk factors were collected: hypertension, hyperlipidemia, NIDDM, IDDM, overweight, current and previous smoking, family history, CVD, PVD and age over 62 years. The highest percentage of patients with hypertension can be found in the 1st district (76.9\%) and in the 18th district (69.6\%). The district with the highest rate of patients with hyperlipidemia is the 8 th district $(78.6 \%)$. The greatest share of patients with NIDDM and IDDM can be found in the 14th district (22\% NIDDM) and in the 6th district (12.5\% IDDM), respectively. Surprisingly, all patients of the 11th district were overweight $(\mathrm{BMI}>25)$. The lowest percentage of overweight patients can be found in the 13th district (57.1\%). With $52 \%$ of all patients being current smokers, the 5th district exhibits the highest prevalence of smoking (among STEMI patients). The 3rd, 8th and 9th districts show the highest shares (3rd district: 29.4\%; 8th and 9th districts: $28.6 \%$ ) of patients with a positive family history. Both, CVD and PVD are most prominent amongst patients in the 1st district (23.1\% CVD, $15.4 \%$ PVD). The 1st district is also the district with the highest share of patients above 62 years of age (84.6\%).

\section{Socio-economic environment}

The following socio-economic indicators were collected at district level: number of residents, pre-tax income, residents per general practitioner, residents per internal specialist, share of population with compulsory education only, share of population with academic degree, and rate of unemployment. The data are summarized in Table 2. All values are shown in means per district over the course of 5 years, 2008-2012. When ranking districts according to their socio-economic environment, as measured by the indicators, ranks increase in terms of pre-tax income and the population share with academic degree, whereas they decrease in terms of the other indicators (bar the number of residents, which is neutral). In the following, we classify districts depending on how many times they are included among the top-5, respectively bottom- 5 , in terms of the socio-economic environment according to the six indicators. The correlation between the socio-economic environment and the district was significant for all indicators, with the exception of pre-tax income and compulsory education only.
The following can be glanced from the table. The 1st district plays a special part, as it has the lowest number of residents but leads on all scores: It has by a large margin the highest income $(€ 51,405)$; exhibits the lowest number of residents per general practitioner $(n=258)$ and per internal specialist $(n=384)$; it features the lowest share of those with compulsory education only $(11.5 \%)$ and the highest share of those with academic degree $(44.3 \%)$ as well as the lowest unemployment rate $(2.0 \%)$. Other districts with high ranks in terms of socio-economic environment are the 8th and 9th district, both of which are among the top- 5 districts according to 5 out of 6 indicators, as well as the 13th district (4 out of 6 in the top-5). At the opposite end, the 10th and 11th district are included among the bottom-5 districts for all indicators, the 20th district is included among the bottom- 5 for 5 out of 6 indicators, and the 15th and 22nd district for 4 out of 6 indicators each. The lowest income $(€ 23,239)$ is found in the 15th district, the highest numbers of residents per general practitioner $(n=2078)$ and per internal specialist $(n=$ 13,377 ) are found in the 14th and 11th district, respectively. The highest share of those with compulsory education (31.2\%) and the lowest share of those with an academic degree $(9.8 \%)$ are found in the 10th and 11th district, respectively. The highest unemployment rate (6.3\%) shows for the 11th district. In summary, we can say that districts $1,8,9,13$ (marked with a single asterisk in Table 2) form a top group in terms of socio-economic environment, whereas districts 10,11, 15, 20 and 22 (marked with a double asterisk in Table 2) form a bottom group.

\section{Socio-economic environment and conventional risk factors}

Columns 2 and 3 of Table 3 report the distribution of conventional risk factors among the whole patient population and among those who died, respectively. As listed in the table ( $p$-Value), the distribution of the conventional risk factors shows a significant difference between dead and surviving patients. Only hypertension and overweight showed no significant difference.

Columns 4-9 of Table 3 report the mean values of the various SES indicators within the patient groups who exhibit (or not) certain conventional risk factors. Given that the indicators are measured at the district level, the mean values then reflect a weighted average of the SES indicators across districts, with the share of patients from district $i$ within risk group $j$ acting as weights applied to the respective value of the SES indicator for district $i$. As a benchmark for comparison we also present for each of the indicators the average across all regions.

As one would expect perhaps, the risk factors hyperlipidemia, overweight and current smoking are associated 
Table 3 Socio-economic aspects and conventional risk factors

\begin{tabular}{|c|c|c|c|c|c|c|c|c|}
\hline & $\begin{array}{l}\text { All } \\
\text { patients } \\
(\%)\end{array}$ & $\begin{array}{l}\text { Dead } \\
(\%)\end{array}$ & $\begin{array}{l}\text { Income } \\
\text { pre-tax }(€)\end{array}$ & $\begin{array}{l}\text { Residents per general } \\
\text { practitioner ( } \mathrm{n} \text { ) }\end{array}$ & $\begin{array}{l}\text { Residents per } \\
\text { internal specialist (n) }\end{array}$ & $\begin{array}{l}\text { Compulsory } \\
\text { education only (\%) }\end{array}$ & $\begin{array}{l}\text { Academic } \\
\text { degree (\%) }\end{array}$ & $\begin{array}{l}\text { Unemployment } \\
\text { rate (\%) }\end{array}$ \\
\hline $\begin{array}{l}\text { Average for } \\
\text { all patients }\end{array}$ & & & 30,318 & 1382 & 5942 & 22.7 & 21.6 & 4.4 \\
\hline \multicolumn{9}{|l|}{ Hypertension } \\
\hline- no & 42.1 & 48.5 & 30,246 & 1381 & 6023 & 22.8 & 21.3 & 4.4 \\
\hline - yes & 57.9 & 51.5 & 30,370 & 1382 & 5883 & 22.7 & 21.9 & 4.4 \\
\hline$p$-Value & & 0.061 & & & & & & \\
\hline \multicolumn{9}{|c|}{ Hyperlipidemia } \\
\hline- no & 45.5 & 63.5 & 30,443 & 1368 & 5825 & 22.7 & 22.1 & 4.4 \\
\hline - yes & 54.5 & 36.5 & 30,213 & 1394 & 6040 & 22.7 & 21.2 & 4.4 \\
\hline - $p$-Value & & $\begin{array}{l}< \\
0.001\end{array}$ & & & & & & \\
\hline \multicolumn{9}{|c|}{ Diabetes mellitus } \\
\hline- no & 82.4 & 73.1 & 30,342 & 1383 & 5908 & 22.6 & 21.7 & 4.4 \\
\hline - NIDDM & 12.3 & 16.7 & 29,529 & 1413 & 6002 & 23.9 & 21.0 & 4.5 \\
\hline$-\mathrm{IDDM}$ & 5.3 & 10.2 & 31,775 & 1298 & 6326 & 22.0 & 22.3 & 4.4 \\
\hline - $p$-Value & & $\begin{array}{l}< \\
0.001\end{array}$ & & & & & & \\
\hline \multicolumn{9}{|c|}{ Overweight (BMI > 25) } \\
\hline- no & 23.2 & 31.3 & 30,920 & 1287 & 5348 & 21.5 & 23.1 & 4.2 \\
\hline - yes & 76.8 & 68.7 & 30,261 & 1397 & 6172 & 22.9 & 21.1 & 4.5 \\
\hline - $p$-Value & & 0.114 & & & & & & \\
\hline \multicolumn{9}{|l|}{ Smoker } \\
\hline- no & 53.2 & 77.2 & 30,423 & 1385 & 5817 & 22.7 & 21.7 & 4.4 \\
\hline - previous & 10.1 & 5.4 & 30,384 & 1356 & 5925 & 22.6 & 21.3 & 4.4 \\
\hline - current & 36.7 & 17.4 & 30,148 & 1385 & 6127 & 22.8 & 21.2 & 4.4 \\
\hline - $p$-Value & & $\begin{array}{l}< \\
0.001\end{array}$ & & & & & & \\
\hline \multicolumn{9}{|c|}{ Family history } \\
\hline- no & 84.5 & 94.0 & 30,283 & 1392 & 6056 & 22.8 & 21.3 & 4.4 \\
\hline - yes & 15.5 & 6.0 & 30,508 & 1330 & 5321 & 22.4 & 23.4 & 4.4 \\
\hline - $p$-Value & & $\begin{array}{l}< \\
0.001\end{array}$ & & & & & & \\
\hline \multicolumn{9}{|l|}{ CVD } \\
\hline- no & 93.4 & 85.0 & 30,225 & 1386 & 5979 & 22.8 & 21.5 & 4.4 \\
\hline - yes & 6.6 & 15.0 & 31,647 & 1319 & 5413 & 21.5 & 23.5 & 4.2 \\
\hline - $p$-Value & & $\begin{array}{l}< \\
0.001\end{array}$ & & & & & & \\
\hline \multicolumn{9}{|l|}{ PVD } \\
\hline- no & 94.8 & 91.0 & 30,240 & 1380 & 5939 & 22.8 & 21.6 & 4.4 \\
\hline - yes & 5.2 & 9.0 & 31,747 & 1413 & 5991 & 21.7 & 22.2 & 4.3 \\
\hline - p-Value & & 0.019 & & & & & & \\
\hline \multicolumn{9}{|l|}{ Age $>62$} \\
\hline- no & 52.2 & 15.0 & 30,016 & 1359 & 5891 & 22.9 & 21.7 & 4.4 \\
\hline - yes & 47.8 & 85.0 & 30.647 & 1.407 & 5.998 & 22.6 & 21.6 & 4.4 \\
\hline - $p$-Value & & $<$ & & & & & & \\
\hline
\end{tabular}


Table 3 Socio-economic aspects and conventional risk factors (Continued)

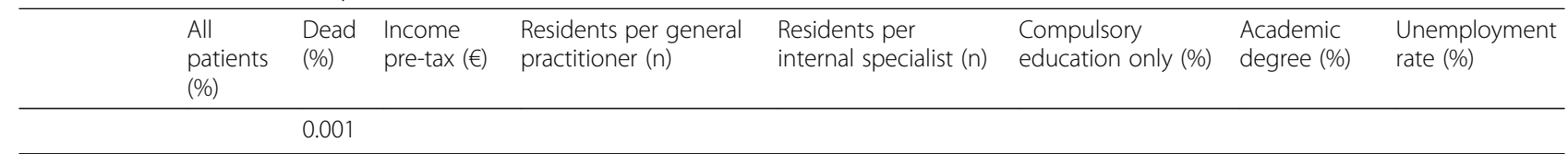

with a disadvantageous socio-economic profile: Patients exhibiting these risk factors tend to be drawn on average from districts with a lower than average income, above average number of residents per general practitioner and internal specialist, above average share of compulsory education, below average share of academic degrees and above average unemployment rate. Conversely, hypertension and CVD are associated with an advantageous socio-economic profile in all categories. In particular patients with CVD are associated with the highest rate of academic degrees (23.5\%) and the lowest rate of compulsory education only (21.5\%). Patients drawn from the age group above 62 tend to be drawn from districts with above average socio-economic environment. While for this group the number of general practitioners per residents is below average, this may be due to the fact that these patients come from districts which exhibit an above average number of internal specialists, the latter being more likely to operate in affluent districts.

While patients without diabetes mellitus tend to be drawn from districts with an above average socio-economic environment (the exception being once more the number of residents per general practitioner), an interesting observation pertains to patients presenting with diabetes mellitus: Very prominently, patients with NIDDM are associated with a strongly disadvantageous SES profile: this group is associated with the lowest income $(€ 29,529)$, the highest rate of compulsory education only $(23.9 \%)$, the lowest rate of academic degrees (21\%) and the highest rate of unemployment (4.5\%). NIDDM patients also tend to be drawn from districts with a high proportion of residents per general practitioner (1413 on average) and per internal specialist (6002 on average).

Conversely, patients with IDDM tend to be drawn from high income districts ( $€ 31,775$ on average) and from districts with a low proportion of residents per general practitioner (1298 on average). They are also associated with a low rate of compulsory education only (22\%) and a high rate of academic degrees (22.3\%). These patients also tend to be drawn from districts with the highest incomes $(€ 31,647)$.

\section{Survival analysis}

To analyze the causal impact on patient survival of conventional risk factors measured at the individual patient level and the socio-economic environment a COX- regression was performed. The socio-economic environment was measured by the various SES indicators for the patient's residential district as well as by a district dummy. While most of the conventional risk factors showed a significant influence on survival, the analysis revealed no influence of the SES indicators. The hazard ratios (HR), 95\% intervals and $p$-values associated with each socio- economic aspect are presented in Table 4 .

There was, however, a significant impact of the residential district per se on survival. This can be seen in the Kaplan Meier analysis, plotting the survival of patients per district. The analysis shows a significant difference between the districts $(p$-Value $=0.028)$. Patients from districts number 13,14, 18 and 19 had the worst outcome as measured by the duration of survival, whereas patients from districts number $9,15,16$ and 20 had the best outcome.

\section{Discussion}

This study examines the impact of socio-economic environment and conventional risk factors on the medical outcome for STEMI patients.

The association between conventional risk factors (hypertension, hyperlipidemia, diabetes mellitus, overweight, smoking, family history, CVD, PVD, age) and medical outcomes for STEMI patients have been well documented in several clinical trials $[2,8-10,12,13$,

Table 4 COX-regression

\begin{tabular}{lllll}
\hline & HR & low95 & up95 & $p$-Value \\
\hline Socio-economic aspect & & & & \\
Income pre-tax (€) & 0.911 & 0.656 & 1.266 & 0.421 \\
Residents per general practitioner (n) & 1.139 & 0.740 & 1.751 & 0.287 \\
Residents per internal specialists (n) & 0.831 & 0.535 & 1.290 & 0.942 \\
Compulsory education only (\%) & 1.012 & 0.948 & 1.080 & 0.703 \\
Academic degree (\%) & 0.989 & 0.943 & 1.037 & 0.791 \\
Unemployment rate (\%) & 0.976 & 0.754 & 1.263 & 0.564 \\
Conventional risk factors & & & & \\
Hypertension & 0.806 & 0.444 & 1.464 & 0.798 \\
Hyperlipidemia & 0.587 & 0.347 & 0.994 & 0.016 \\
Diabetes mellitus & 1.484 & 1.021 & 2.157 & $<0.001$ \\
Overweight (BMI $>$ 25) & 0.706 & 0.403 & 1.237 & 0.072 \\
Smoker & 0.962 & 0.698 & 1.325 & 0.005 \\
Family history & 0.724 & 0.336 & 1.560 & 0.127 \\
CVD & 1.656 & 0.782 & 3.510 & 0.001 \\
PVD & 1.794 & 0.828 & 3.887 & 0.003 \\
Age > 62 & 4.519 & 2.378 & 8.586 & $<0.001$ \\
\hline
\end{tabular}


16]. Similarly, the importance of the optimal management of conventional risk factors and its benefit for medical outcomes has been confirmed in various studies and can be found in guidelines of the European Society of Cardiology $[2,14]$.

The socio-economic environment has been shown to be strongly associated with patient risk factors and health outcomes, in general $[17,20,30]$ and for CAD [12, 18, 23]. According to our ranking analysis described earlier, districts $1,8,9$ and 13 form a top group in respect to socio-economic environment, whereas districts $10,11,15$, 20 and 22 form a bottom group. Of the districts with a high socio-economic environment, the 1st district, corresponding to the "inner city" stands out by leading on all indicators. This main business, shopping and government district is special not the least because it is not really a residential district owing to high rents. Indeed, the high share of patients aged above 62 for the 1st district can be explained by the fact that it is mostly elderly persons benefitting from rent protection who can still afford residence in this area. Nevertheless, doctors tend to do business in the 1st district due to the prestige and closeness to many employers, which explains the low shares of residents per general practitioner and internal specialist. Aside from the inner city, districts number 8, 9, 13 and 19 also feature high incomes, high rates of academic degrees and low rates of unemployment.

The lowest income can be found in the predominantly working class districts number 10,15 and 20 . These districts also have low rates of academic degrees and high rates of compulsory education only. Districts number 15 and 20 also show high rates of unemployment. The 11th district exhibits the highest number of residents per internal specialist and the second highest number of residents per general practitioner. It is also the district with the lowest rate of academic degrees and the highest rate of unemployment. The reason for the poor density of doctors in this district might be the fact, that there is no hospital in the 11th district. A similar phenomenon can be found in the 21st district.

It is notable that across districts there is significant correlation between the socio-economic indicators, including the density of health care provision, which illustrates that socio-economic aspects are tightly interwoven and influence each other.

\section{Conventional risk factors and socio-economic environment}

By considering the joint distribution of SES indicators and conventional risk factors we are able to study at population level the association between SES and risk factors. Generally, the conventional risk factors of this study go along with the literature (see above). All conventional risk factors, aside from hypertension and overweight, were highly significant in relation to the survival of patients, and hypertension shows at least a clear trend with a $p$-value of 0.061 (Table 3).

A clear socio-economic profile of the conventional risk factors is shown in Table 3. Conventional risk factors associated with a good socio-economic profile are hypertension and CVD. The risk factors hyperlipidemia, overweight and current smoking are associated with a poorer SES profile. This suggests that poor socio-economic environments are not uniformly associated with higher conventional risk factors. The above average SES profile associated with the group aged above 62 suggests that on average the elderly (and, thus, those exposed to higher STEMI risks) tend to live in better and potentially protective socio-economic environments. Conversely, patients below 62 tend to be drawn from poorer socio-economic environments. While we cannot claim causality, the association is suggestive of a poor socio-economic environment being conducive to premature (in terms of age) STEMI events.

A particularly interesting finding pertains to the role of diabetes mellitus as a risk factor.

Specifically, patients with IDDM are associated with the highest income and the highest proportion of residents per general practitioner. They also tend to come from districts with a low rate of compulsory education only and a high rate of academic degrees. Conversely, patients with NIDDM tend to come from disadvantaged districts with the lowest income, the highest rate of compulsory education only, the lowest rate of academic degrees and the highest rate of unemployment. NIDDM patients are also associated with the worst proportions of residents per general practitioner and internal specialist, respectively. Notably, IDDM, as compared to NIDDM, is a more serious and advanced stadium of diabetes mellitus. This finding suggests the presence of selection: Patients who benefit from a good socio-economic environment tend to show as STEMI patients only when facing a severe diagnosis, while milder risk factors seem to be under better control. In contrast, patients drawn from poorer environments show as STEMI also under milder conditions, suggesting a weaker control of cardiac risks. Again, we can take this as evidence for a good socio-economic environment having a protective impact.

The study of Jones et al. [18] demonstrated that a low socio-economic status is significantly associated with an adverse prognosis after PCI using mortality as endpoint. It also shows, that patients with a low SES have higher rates of conventional risk factors, which is in line with the correlation between conventional risk factors and socio- economic environment documented in the present study.

\section{Survival}

A COX-regression and a Kaplan Meier survival analysis was conducted to explore the impact of conventional 
risk factors as well as of the socio-economic environment at a patient's residential district on individual survival. The results of the COX regression of the conventional risk factors in Table 4 showed that hyperlipidemia, diabetes mellitus, smoking, CVD, PVD and age have a significant influence on survival. Indeed, this goes along with other studies [3, 6-8, 10, 11, 14]. Hypertension, overweight and family history showed no significant influence on survival in the COX regression.

The COX-regression showed no significant impact of the indicators of the socio-economic environment on individual survival (Table 4). Given the expected clear impact of conventional risk factors on survival, which are directly controlled for at the individual level, the finding that the socio-economic environment at the individual's place of residence has no significant effect on survival would suggest that the socio-economic environment has no direct impact on treatment outcomes beyond determining the patient's conventional risk. Whether or not this is true is difficult to gauge. On the one hand, there is a positive correlation between socio-economic environment and conventional risk factors at population level; on the other hand, it is well known that this result does not suggest such a relationship at the individual level but may rather be down to compositional effects.

Our analysis revealed, however, a significant variance of survival across the districts (as measured by their postcode) of Vienna ( $p$-Value $=0.028)$. According to the Kaplan Meier analysis the worst survival outcomes are found in districts $13,14,18$ and 19 , whereas the best outcomes are found in districts number 9, 15, 16 and 20 . While one might expect that the post code might serve as a summary measure of the socio-economic environment, the apparent lack of correlation between survival outcome and the ranking of districts in terms of their socio-economic environment (13 and 9 among the top-5; 15 and 20 among the bottom 5) is striking. Considering individual districts shows that the 14th district performs worst in terms of the number of residents per general practitioner. In contrast, the 9th district is the second best district in terms of the density of internal specialists. While this may be suggesting a role for primary care provision in terms of explaining survival, the result may also be down to location: The General Hospital of Vienna (AKH Wien) being situated in the 9th district is likely to explain the high density of internal specialists, but it is also indicative of short travelling times. In contrast, the 14th district is located relatively further off. The bad survival rates in districts number 13, 18 and 19 do not go along with the data in this study, as the SES indicators of these districts are above average. Conversely, the unexpectedly good survival rates in districts 15 and 20 are out of line with the SES indicators of these districts being below average. All of this suggests a need for further exploration of possibly unobserved district-specific factors.

\section{Limitations}

This study has a number of limitations. The study is an observational analysis of a single center. The data set includes most clinical variables known. However, the results might be confounded by variables which were not collected. In contrast to the conventional risk factors, it was impossible to collect socio-economic data for each individual patient but only at district level. While we could synchronize the socio-economic environment with the postal code of each patient, the impossibility of directly measuring the SES of a patient rules out the identification of any causal relationship between socio-economic data and survival. This indicates a distinct need for the availability of matched clinical and socio-economic data at individual level.

\section{Conclusions}

This study has investigated the socio-economic environment and the conventional risk factors of patients who underwent PCI after STEMI. The study demonstrated an association between the distribution of socio-economic status and conventional risk factors across districts in Vienna, Austria. The conventional risk factors, in turn, showed significant impact on the survival for STEMI patients.

In summary, the study could provide intuitive evidence on the link between socio-economic environment and conventional risk factors at population level and the link between conventional risk factors and survival both at the population and at the individual level.

The study suggests that knowledge of the socio- economic environment within (residential) districts is important for understanding the prevalence of cardiovascular risk factors among the population at district level. Such knowledge may allow for better prevention strategies and improving the provision of treatment courses for CAD. Therefore SES indicators should be integrated into guidelines, prognostic calculations and management of cardiovascular disease, especially in STEMI patients.

\section{Abbreviations \\ ACS: Acute coronary syndrome; AHA: American Heart Association; CABG: Coronary artery bypass grafting; CAD: Coronary artery disease; CCS: Canadian cardiovascular society; CVD: Cerebrovascular disease; ESC: European Society of Cardiology; IDDM: Insulin-dependent diabetes mellitus; MI: Myocardial infarction; NIDDM: Non- insulin-dependent diabetes mellitus; NYHA: New York heart association; PCl: Percutaneous coronary intervention; PVD: Peripheral vascular disease; SCAD: Stable coronary artery disease.; SES: Socio-economic status; STEMI: ST-segment elevation myocardial infarction; UA: Unstable-angina; WHO: World Health Organization}

\section{Acknowledgments}

We want to thank Harald Allacher and the RDA team - especially Prof. Susanne Rockenschaub for the good collaboration over the past months. 


\section{Funding}

There is no funding for this study.

\section{Availability of data and materials}

The datasets used and/or analyzed during the current study are available from the corresponding author on request.

\section{Authors' contributions}

CR wrote the paper, performed the statistical analysis, and designed the study. MK participated in the design of the study and writing of the paper and provided critical feedback on the statistical analysis and drafts. RB provided critical feedback and commented on drafts. All authors read and approved the final manuscript.

\section{Authors' information}

$C R$ is a specialist in cardiology at the Medical University of Vienna. RB is a specialist in cardiology at the Hospital of St. John of God in Eisenstadt. MK is a research group leader at the Wittgenstein Centre (IIASA, OEAWNID, WU) and Vienna Institute of Demography.

\section{Ethics approval and consent to participate}

This study is approved by the ethics committee of the Medical University of Vienna (EK Nr. 972/2011) and is also in line with the Declaration of Helsinki.

\section{Consent for publication}

Not applicable.

\section{Competing interests}

The authors declare that they have no competing interests.

\section{Publisher's Note}

Springer Nature remains neutral with regard to jurisdictional claims in published maps and institutional affiliations.

\section{Author details}

'Department of Internal Medicine II, Cardiology, Medical University of Vienna, Waehringer Guertel 18-20, 1090 Vienna, Austria. ${ }^{2}$ Department of Internal Medicine I, Cardiology and Nephrology, Hospital of St. John of God, Johannes von Gott-Platz 1, 7000 Eisenstadt, Austria. ${ }^{3}$ Wittgenstein Centre (WU, VID/ÖAW, IIASA), Institute for Applied Systems Analysis and Vienna Institute of Demography, Welthandelsplatz 2/Level 2, 1020 Vienna, Austria.

\section{Received: 13 August 2018 Accepted: 13 May 2019}

\section{Published online: 23 May 2019}

\section{References}

1. WHO dw. World Health Organization. The top 10 causes of death in the world 2015. WHO. 2017 [accessed 2017 April 30]. Available: http://www. who.int/mediacentre/factsheets/fs310/en/. 2016.

2. Mozaffarian D, Benjamin EJ, Go AS, Arnett DK, Blaha MJ, Cushman M, et al. Heart disease and stroke Statistics-2016 update: a report from the American Heart Association. Circulation. 2016;133(4):e38-e360.

3. Steg PG, James SK, Atar D, Badano LP, Blomstrom-Lundqvist C, Borger MA, et al. ESC guidelines for the management of acute myocardial infarction in patients presenting with ST-segment elevation. Eur Heart J. 2012;33(20): 2569-619.

4. Statistik Austria; Gesundheitsstatistik. Jahrbuch der Gesundheitsstatistik 2014. Statistik Austria. Dec. 2015. [citied 2016 May 1]. Available: http://www. statistik.at/web_de/statistiken/menschen_und_gesellschaft/gesundheit/ todesursachen/todesursachen_im_ueberblick/index.html. 2014.

5. Montalescot G, Sechtem U, Achenbach S, Andreotti F, Arden C, Budaj A, et al. 2013 ESC guidelines on the management of stable coronary artery disease: the task force on the management of stable coronary artery disease of the European Society of Cardiology. Eur Heart J. 2013;34(38):2949-3003.

6. Bayturan O, Kapadia S, Nicholls SJ, Tuzcu EM, Shao M, Uno K, et al. Clinical predictors of plaque progression despite very low levels of low-density lipoprotein cholesterol. J Am Coll Cardiol. 2010;55(24):2736-42.

7. Chhatriwalla AK, Nicholls SJ, Wang TH, Wolski K, Sipahi I, Crowe T, et al. Low levels of low-density lipoprotein cholesterol and blood pressure and progression of coronary atherosclerosis. J Am Coll Cardiol. 2009; 53(13):1110-5.
8. Kronmal RA, McClelland RL, Detrano R, Shea S, Lima JA, Cushman M, et al. Risk factors for the progression of coronary artery calcification in asymptomatic subjects: results from the multi-ethnic study of atherosclerosis (MESA). Circulation. 2007;115(21):2722-30.

9. Nicholls SJ, Hsu A, Wolski K, Hu B, Bayturan O, Lavoie A, et al. Intravascular ultrasound-derived measures of coronary atherosclerotic plaque burden and clinical outcome. J Am Coll Cardiol. 2010;55(21): 2399-407.

10. Pekkanen J, Linn S, Heiss G, Suchindran CM, Leon A, Rifkind BM, et al. Tenyear mortality from cardiovascular disease in relation to cholesterol level among men with and without preexisting cardiovascular disease. N Engl J Med. 1990;322(24):1700-7.

11. Bayturan O, Tuzcu EM, Uno K, Lavoie AJ, Hu T, Shreevatsa A, et al. Comparison of rates of progression of coronary atherosclerosis in patients with diabetes mellitus versus those with the metabolic syndrome. Am J Cardiol. 2010;105(12):1735-9.

12. Perk J, De Backer G, Gohlke H, Graham I, Reiner Z, Verschuren M, et al. European guidelines on cardiovascular disease prevention in clinical practice (version 2012). The fifth joint task force of the European Society of Cardiology and Other Societies on cardiovascular disease prevention in clinical practice (constituted by representatives of nine societies and by invited experts). Eur Heart J. 2012;33(13):1635-701.

13. Frey P, Waters DD, DeMicco DA, Breazna A, Samuels L, Pipe A, et al. Impact of smoking on cardiovascular events in patients with coronary disease receiving contemporary medical therapy (from the treating to new targets [TNT] and the incremental decrease in end points through aggressive lipid lowering [IDEAL] trials). Am J Cardiol. 2011;107(2):145-50.

14. Otaki Y, Gransar H, Berman DS, Cheng WY, Dey D, Lin FY, et al. Impact of family history of coronary artery disease in young individuals (from the CONFIRM registry). Am J Cardiol. 2013;111(8):1081-6.

15. Oakes JM, Rossi PH. The measurement of SES in health research: current practice and steps toward a new approach. Soc Sci Med. 2003;56(4):769-84.

16. Adler NE, Ostrove JM. Socioeconomic status and health: what we know and what we don't. Ann N Y Acad Sci. 1999:896:3-15.

17. Reijneveld SA. Neighbourhood socioeconomic context and self reported health and smoking: a secondary analysis of data on seven cities. J Epidemiol Community Health. 2002;56(12):935-42.

18. Jones DA, Howard JP, Rathod KS, Gallagher SM, Knight CJ, Jain AK, et al. The impact of socio-economic status on all-cause mortality after percutaneous coronary intervention: an observational cohort study of 13,770 patients. Eurolntervention. 2015;10(10):e1-8.

19. Suadicani P, Hein HO, Gyntelberg F. Socioeconomic status and ischaemic heart disease mortality in middle-aged men: importance of the duration of follow-up. The Copenhagen male study. Int J Epidemiol. 2001;30(2):248-55.

20. Davey-Smith G, Dorling D, Mitchell R, Shaw M. Health inequalities in Britain: continuing increases up to the end of the 20th century. J Epidemiol Community Health. 2002;56(6):434-5.

21. Denvir MA, Lee AJ, Rysdale J, Walker A, Eteiba H, Starkey IR, et al. Influence of socioeconomic status on clinical outcomes and quality of life after percutaneous coronary intervention. J Epidemiol Community Health. 2006; 60(12):1085-8.

22. Gibson PH, Croal BL, Cuthbertson BH, Gibson G, Jeffrey RR, Buchan KG, et al. Socio-economic status and early outcome from coronary artery bypass grafting. Heart. 2009;95(10):793-8.

23. Taylor FC, Ascione R, Rees K, Narayan P, Angelini GD. Socioeconomic deprivation is a predictor of poor postoperative cardiovascular outcomes in patients undergoing coronary artery bypass grafting. Heart. 2003;89(9):1062-6.

24. Dalen M, Ivert T, Holzmann MJ, Sartipy U. Household disposable income and long-term survival after cardiac surgery: a Swedish Nationwide cohort study in 100,534 patients. J Am Coll Cardiol. 2015;66(17):1888-97.

25. Zaborski L, Zagozdzon P. Analysis of cardiovascular mortality in the population of three cities. Wiad Lek (Warsaw, Poland: 1960). 2002;55(Suppl 1):576-80.

26. Townsend PP, Health P, Deprivation P, Townsend P, Beattie Health PA. Deprivation published by Croom helm 212pp pound19.95 0-7099-4351-2 [formula: see text]. Nurs Stand (Royal College of Nursing (Great Britain): 1987). 1988;2(17):34

27. Macintyre S, Ellaway A, Cummins S. Place effects on health: how can we conceptualise, operationalise and measure them? Soc Sci Med. 2002;55(1): 125-39. 
28. Graley CE, May KF, McCoy DC. Postcode lotteries in public health--the NHS Health checks Programme in north West London. BMC Public Health. 2011; 11:738.

29. Ecob R. A multilevel modelling approach to examining the effects of area of residence on Health and functioning. J R Stat Soc Ser A. 1996;159(1):61-75.

30. Cummins S, Stafford M, Macintyre S, Marmot M, Ellaway A. Neighbourhood environment and its association with self rated health: evidence from Scotland and England. J Epidemiol Community Health. 2005;59(3):207-13.

31. Jeong J, Ro YS, Shin SD, Song KJ, Hong KJ, Ahn KO. Association of time from arrest to percutaneous coronary intervention with survival outcomes after out-of-hospital cardiac arrest. Resuscitation. 2017;115:148-54.

32. Montone RA, Niccoli G, Minelli S, Fracassi F, Vetrugno V, Aurigemma C, et al. Clinical outcome and correlates of coronary microvascular obstruction in latecomers after acute myocardial infarction. Int J Cardiol. 2017;236:30-5.

33. Townsend P, Phillimore P. Health and Deprivation. R Coll Nurs. 1988;2(17):34

34. Statistik Austria; income [accessed 2016 July 1]: http://www.statistik.at/web_ de/statistiken/wirtschaft/oeffentliche_finanzen_und_steuern/ steuerstatistiken/lohnsteuerstatistik/index.html. 2016.

35. Stadt Wien, Magistratsabteilung 23 - Wirtschaft, Arbeit und Statistik; income [accessed 2016 July 1]: https://www.wien.gv.at/statistik/arbeitsmarkt/ tabellen/einkommen-zr.html. 2016.

36. Statistik Austria; population [accessed 2016 July 1]: http://www.statistik.at/ web_de/statistiken/menschen_und_gesellschaft/bevoelkerung/ volkszaehlungen_registerzaehlungen_abgestimmte_erwerbsstatistik/ bevoelkerungsstand/078392.html. 2016.

37. Stadt Wien, Magistratsabteilung 23 - Wirtschaft, Arbeit und Statistik; population [accessed 2016 July 1]: https://www.wien.gv.at/statistik/ bevoelkerung/tabellen/bevoelkerung-bez-zr.html. 2016

38. ÄK Wien p. Ärztekammer Wien; physician [accessed 2016 July 1]: http:// www.praxisplan.at/doctor_search.php. 2016

39. Stadt Wien, Magistratsabteilung 23 - Wirtschaft, Arbeit und Statistik; physician [accessed 2016 July 1]: https://www.wien.gv.at/statistik/soziales/ tabellen/aerzte-apotheken-zr.html; https://www.wien.gv.at/kontakte/ma23/. 2016.

40. Stadt Wien, Magistratsabteilung 23 - Wirtschaft, Arbeit und Statistik unemployment [accessed 2016 July 1]: https://www.wien.gv.at/kontakte/ ma23/. 2016.

41. Statistik Austria; unemployment [accessed 2016 July 1]: http://www.statistik. at/web_de/statistiken/menschen_und_gesellschaft/arbeitsmarkt/arbeitslose arbeitssuchende/index.html. 2016.

42. Stadt Wien, Magistratsabteilung 23 - Wirtschaft, Arbeit und Statistik; education [accessed 2016 July 1]: https://www.wien.gv.at/kontakte/ma23/. 2016.

43. Statistik Austria; education [accessed 2016 July 1]: http://www.statistik.at/ web_de/statistiken/menschen_und_gesellschaft/bildung_und_kultur/index. html. 2016.

Ready to submit your research? Choose BMC and benefit from:

- fast, convenient online submission

- thorough peer review by experienced researchers in your field

- rapid publication on acceptance

- support for research data, including large and complex data types

- gold Open Access which fosters wider collaboration and increased citations

- maximum visibility for your research: over $100 \mathrm{M}$ website views per year

At $\mathrm{BMC}$, research is always in progress.

Learn more biomedcentral.com/submissions 